\title{
Comment on 'Techno therapy or nurtured niches?' by Hommels et al. [Res. Policy 36 (7) (2007)]
}

\author{
Frank W. Geels ${ }^{\mathrm{a}, *}$, Johan Schot ${ }^{\mathrm{b}}$ \\ ${ }^{a}$ Eindhoven University, Department of Technology Management, IPO 2.10, PO Box 513, 5600 MBEindhoven, Netherlands \\ ${ }^{\mathrm{b}}$ Eindhoven University, Department of Technology Management, IPO 2.25, PO Box 513, 5600 MBEindhoven, Netherlands
}

Received 22 June 2007; accepted 22 June 2007

In their article 'Techno therapy or nurtured niches', Hommels et al. (2007) compare two policy approaches for radical innovations: their PROTEE approach and strategic niche management (SNM), to which we have contributed. Their comparison includes some critical discussion of SNM, which we welcome. However, they also provide some unfortunate misrepresentations, which we would like to correct because they are important for important broader issues.

The first broader issue is that different types of innovations provide different policy challenges. Hommels et al. investigate the automation of the Delta-Sealand terminal in Rotterdam's harbour. Such local innovations, introduced by a company for commercial reasons, differ in two ways from SNM: (1) SNM is about socially desirable innovations, oriented towards for instance long-term goals such as sustainability, (2) SNM addresses system innovations and transitions, where novelties have to fight against existing systems and often face a mis-match with regard to existing infrastructure, user practices, regulations, etc. Hence, innovations in SNM studies, for example battery-electric vehicles (BEV), cannot compete on mainstream markets. This makes the policy challenge in SNM different from PROTEE.

DOI of the original article:10.1016/j.respol.2007.04.002.

* Corresponding author. Tel.: +31 40247 5414; fax: +31 402444602.

E-mail addresses: F.W.Geels@tm.tue.nl (F.W. Geels), j.w.schot@tue.nl (J. Schot).
Because Hommels et al. do not account for this difference, misunderstandings arise, for instance, when they claim that "In the SNM approach, radical innovations are initially developed in protected niches after which they are confronted with the "real world outside." This claim is surprising, because SNM precisely aims to move innovations from the R\&D phase into the wider world. Experiments in real-life contexts, for instance, make innovations 'vulnerable' to feedback from users, policy makers and other stakeholders (we do see that SNM can further profit here from the PROTEE approach). However, such a move would be impossible without well chosen protection (subsidies, other benefits) against mainstream market selection (associated with the existing regime). That is why the experimental projects are conceptualised as protected spaces or proto-markets. But within such 'technological niches' the main aim is still confrontation between technology and context, enabling user-producer interactions, learning processes, network development, the articulation of expectations, and explorations of what sustainable development can be. Protection is thus not the main goal of SNM, but a means to facilitate confrontations when regular markets do not exist and prevailing regimes exclude the development of pathways which may lead to more sustainable development.

SNM investigates which designs of experimental projects work well and which not. Hommels et al. make the logical error of taking failed projects, which were studied ex-post with an SNM approach, as indication of 
failures of SNM as such. We refer in particular to their discussion of the BEV experiment at Rügen and the conclusion that projects were often overly self-contained. Because SNM-scholars draw similar conclusions, this cannot be used to distinguish PROTEE from SNM. Similarly, the suggestion that, at the level of niches, obduracy of sociotechnology is hardly taken into account cannot be substantiated. We refer to the extensive discussions on barriers for change and difficult alignment processes within niches. More importantly, recent SNM studies have developed a view on how to overcome obduracy. This view focuses on studying sequences of projects, relationships between niches and regimes, the emergence of longer-term learning trajectories and transition pathways (Smith, 2006; Geels and Raven, 2006; Geels and Schot, 2007). Unfortunately, Hommels et al. do not address these recent developments. Their discussion is too much based on a limited selection of SNM-literature, particularly a grey literature workbook for policy makers (Weber et al., 1999).

A second broader issue is the uneasy relation between Science and Technology Studies (STS) and evolutionary economics (EE). We read Hommels et al.'s criticism on 'natural trajectories' (a term from Nelson and Winter) as "developing according to an internal, 'natural' logic" as broader critique of EE. Related to this issue is the claim that SNM is based on path dependence, and that "one of the problems of models of path dependency is that they usually ignore the role of agency." This argument is then extrapolated to SNM, leading to the surprising claim that SNM pays little attention to alternative paths and learning processes. We disagree with these claims, because SNM pays explicit attention to alternative designs, actors and learning processes. Although the authors cite the book by Garud and Karnøe (2001), they fail to take seriously the distinction between path dependence (based on impersonal mechanisms such as increasing returns to adoption) and path creation (where paths arise through enactment). SNM belongs to the tradition that stresses path creation, alternatives, diversity, and agency. The general point we would like to make is that dichotomous representations are not very productive. The claim that STS approaches pay more attention to actors may have been relevant in the 1980s, when EE emerged. But since then several EE-scholars have tried to incorporate agency, replacing for example blind variation with directed (or Lamarckian) variation, as is also the case for SNM. STS does not have a monopoly on agency. Misrepresentations also exist within EE, where STS is sometimes portrayed as being pre-occupied with public participation while neglecting the importance of markets. In our view, much can be gained from crossovers between STS and EE. We flag SNM and the underlying quasi-evolutionary perspective as promising in this respect, and welcome the invitation by Hommels et al. to further explore conceptual connections.

\section{References}

Garud, R., Karnøe, P. (Eds.), 2001. Path Dependence and Creation. Lawrence Earlbaum Associates, Mahwah, NJ.

Geels, F.W., Raven, R.P.J.M., 2006. Non-linearity and expectations in niche-development trajectories: ups and downs in Dutch biogas development (1973-2003). Technology Analysis \& Strategic Management 18 (3/4), 375-392.

Geels, F.W., Schot, J.W., 2007. Typology of sociotechnical transition pathways. Research Policy 36 (3), 399-417.

Hommels, A., Peters, P., Bijker, W.E., 2007. Techno therapy or nurtured niches? Technology studies and the evaluation of radical innovations. Research Policy 36 (7), XXX.

Smith, A., 2006. Green niches in sustainable development: The case of organic food in the United Kingdom. Environment and Planning C: Government and Policy 24, 439-458.

Weber, M., Hoogma, R., Lane, B., Schot, J., 1999. Experimening with Sustainable Transport Innovations: A Workbook for Strategic Niche Management. Twente University, Seville, Enschede. 